\title{
PANDEMIA DE COVID-19 E OS ESFORÇOS DA CIÊNCIA PARA COMBATER O NOVO CORONAVÍRUS
}

\author{
COVID-19 PANDEMIC AND SCIENTIFIC EFFORTS TO COMBAT THE NEW CORONAVIRUS
}

DOI: 10.16891/2317-434X.v8.e1.a2020.pp360-361

Vanderlan Nogueira Holanda

Departamento de Bioquímica, Centro de Biociências Universidade Federal de Pernambuco Instituto Aggeu Magalhães - IAM/FIOCRUZ E-mail: vanderlan.nogueira@hotmail.com

No dia 30 de janeiro de 2020 foi declarado, pela Organização Mundial de Saúde, um surto de Coronavírus que chamou a atenção das autoridades de todo o mundo. $\mathrm{O}$ aumento exponencial dos casos de COVID-19, doença causada pelo SARS-CoV-2, logo se tornou uma emergência de saúde pública de interesse internacional (ZHAI et al., 2020). O novo Coronavírus é o agente infeccioso responsável pela pandemia COVID-19, doença que pode se apresentar desde sintomas clássicos de gripe, como dor no corpo, febre e irritação de garganta até a forma mais grave, caracterizada por insuficiência respiratória aguda, que pode resultar na morte (CHEN et al., 2020; LAU et al., 2020).

Devido a falta de uma vacina que impeça a infecção pelo SARS-CoV-2, as medidas de combate à COVID-19 se constituem da realização de quarentena e busca por drogas capazes de reverterem a forma grave da doença. A realização de quarentena é uma medida comprovadamente eficaz contra a disseminação do vírus e contribui para a diminuição de novos casos (LIN, PENG \& TSAI, 2010), sobretudo a ocorrência da doença em indivíduos que compõem grupos de risco como idosos; indivíduos com comorbidades, doenças respiratórias, etc. Somado a esta medida, pesquisadores de várias nacionalidades não medem esforços para a descoberta de um tratamento farmacológico eficaz para o tratamento da COVID-19 (UL QAMAR et al., 2020).

Recentemente, alguns estudos in vitro e ensaios clínicos sugeriram que a cloroquina e hidroxicloroquina, medicamentos utilizados para tratamento da malária e como imunomodulador são eficazes na redução da replicação viral (GAUTRET et al., 2020). Adicionalmente, o efeito antiviral desses compostos sobre outros tipos de viros já foi reportada como o vírus da imunodeficiência humana (PATON, ABOULHAB \& KARIM, 2002), Zika (ZHANG et al., 2019) e SARS-CoV-1(BECK et al., 2020). O provável mecanismo de ação antiviral pode estar relacionado à interferência na ligação do vírus aos receptores de superfície celular (WANG et al., 2015) e na modificação pós-traducional de proteínas virais (RANDOLPH, WINKLER \& STOLLAR, 1990). Não se pode descartar a possibilidade da ação imunomoduladora destes compostos contribuírem para o tratamento da COVID-19, pois tem sido observado que em uma parte dos pacientes com a forma grave da doença apresenta perfil elevado de citocinas pró-inflamatórias (ZHANG et al., 2020). Apesar desses resultados e do aparente efeito promissor da cloroquian e seu derivado, é necessária a realização de estudos adicionais que comprovem a eficácia e a segurança desses compostos para a admnistação em casos de COVID-19.

Diante desse cenário, medidas de saúde e vigilância farmacológica não podem ser esquecidas. A automedicação pode causar danos à saúde e não deve ser incentivada. Dentre as formas efetivas de prevenção e combate à COVID-19, estão a realização de quarentena e o seguimento das orientações dos órgãos nacionais e internacionais de saúde. Neste primeiro número do volume 8 (V. 8, N. 1 (2020), a Revista Interfaces: Saúde, Humanas e Tecnologia apresenta artigos originais, artigos de revisão e relatos de casos que contribuem para o desenvolvimento da área interdisciplinar ao mesmo tempo que apresentam temas importantes para as demais áreas específicas do conhecimento. Convidamos todos a navegar no sumário da revista para acessar os artigos e outros itens de interesse. 


\section{- revisto

\section{REFERÊNCIAS}

BECK, B. R.; SHIN, B.; CHOI, Y.; PARK, S. et al. Predicting commercially available antiviral drugs that may act on the novel coronavirus (SARS-CoV-2) through a drug-target interaction deep learning model. Computational and Structural Biotechnology Journal, 2020/03/30/ 2020.

CHEN, N.; ZHOU, M.; DONG, X.; QU, J. et al. Epidemiological and clinical characteristics of 99 cases of 2019 novel coronavirus pneumonia in Wuhan, China: a descriptive study. 395, n. 10223, p. 507-513, 2020.

GAUTRET, P.; LAGIER, J.-C.; PAROLA, P.; HOANG, V. T. et al. Hydroxychloroquine and azithromycin as a treatment of COVID-19: results of an open-label nonrandomized clinical trial. International Journal of Antimicrobial Agents, p. 105949, 2020/03/20/ 2020.

LAU, H.; KHOSRAWIPOUR, V.; KOCBACH, P.; MIKOLAJCZYK, A. et al. Internationally lost COVID-19 cases. Journal of Microbiology, Immunology and Infection, 2020/03/14/ 2020.

LIN, E. C. L.; PENG, Y. C.; TSAI, J. C. H. J. A. j. o. i. c. Lessons learned from the anti-SARS quarantine experience in a hospital-based fever screening station in Taiwan. 38, n. 4, p. 302-307, 2010.

PATON, N. I.; ABOULHAB, J.; KARIM, F. Hydroxychloroquine, hydroxycarbamide, and didanosine as economic treatment for HIV-1. The Lancet, 359, n. 9318, p. 1667-1668, 2002/05/11/ 2002.
RANDOLPH, V. B.; WINKLER, G.; STOLLAR, V. J. V. Acidotropic amines inhibit proteolytic processing of flavivirus prM protein. 174, n. 2, p. 450-458, 1990.

UL QAMAR, M. T.; ALQAHTANI, S. M.; ALAMRI, M. A.; CHEN, L.-L. Structural basis of SARS-CoV-2 3CLpro and anti-COVID-19 drug discovery from medicinal plants $\uparrow$. Journal of Pharmaceutical Analysis, 2020/03/26/ 2020.

WANG, L.-F.; LIN, Y.-S.; HUANG, N.-C.; YU, C.-Y. et al. Hydroxychloroquine-inhibited dengue virus is associated with host defense machinery. 35, n. 3, p. 143$156,2015$.

ZHAI, P.; DING, Y.; WU, X.; LONG, J. et al. The epidemiology, diagnosis and treatment of COVID-19. International Journal of Antimicrobial Agents, p. 105955, 2020/03/28/ 2020 .

ZHANG, C.; WU, Z.; LI, J.-W.; ZHAO, H. et al. The cytokine release syndrome (CRS) of severe COVID-19 and Interleukin-6 receptor (IL-6R) antagonist Tocilizumab may be the key to reduce the mortality. International Journal of Antimicrobial Agents, p. 105954, 2020/03/29/ 2020.

ZHANG, S.; YI, C.; LI, C.; ZHANG, F. et al. Chloroquine inhibits endosomal viral RNA release and autophagydependent viral replication and effectively prevents maternal to fetal transmission of Zika virus. Antiviral Research, 169, p. 104547, 2019/09/01/ 2019. 